\title{
Imagination and Self Disorders in Schizophrenia: A Review
}

\author{
Tudi Gozéa-c Istvan Fazakas ${ }^{c}$ \\ ${ }^{a}$ Service de Psychiatrie, Psychothérapies et Art-Thérapie, CHU de Toulouse, Toulouse, France; ${ }^{b}$ Equipe de Recherche \\ sur les Rationalités Philosophiques et les Savoirs, Université Toulouse Jean Jaurès, Toulouse, France; ' Institut für \\ Transzendentalphilosophie und Phänomenologie, Wuppertal University, Wuppertal, Germany
}

\section{Keywords}

Imagination · Schizophrenia spectrum disorders · Phantasy · Self disorders · Phenomenology · Corporeality

\begin{abstract}
Anomalies of imagination are frequent and handicapping in schizophrenia spectrum disorders (SSDs) but neglected in psychopathology due to the lack of a conceptual framework to model disorders of imagination. Recently, the link between minimal self disorders and pathology of imagination has been emphasized. The aim of the present article is to discuss this initiative by stressing their paradigm drawing on the recent imaginary turn in phenomenological research. Although this field of research is currently very active in philosophy, there are very few translational approaches in psychopathology or cognitive sciences. In this paper, we examine how contemporary research concerning fantasy and imagination can lead to the elaboration of an epistemological and phenomenological framework for schizophrenia research. We first examine the psychopathological literature on anomalous fantasy and imagination in SSDs. Then we propose an exhaustive overview of the imaginary turn of philosophical phenomenology. Further, we examine the theoretical and practical implications of such a recasting of phenomenological research. We show how fantasy and
\end{abstract}

imagination are involved in the embodiment process, and how identity and imagination are interlinked. Finally, we propose an overview of the possible implications for the understanding of psychotherapeutic processes and recovery strategies.

(c) 2020 S. Karger AG, Basel

We are such stuff as dreams are made on, and our little life is rounded with a sleep.

(The Tempest)

William Shakespeare

\section{Introduction}

In this journal, Rasmussen et al. [1] have recently raised attention to anomalies of imagination in psychopathology. They claim that these troubles are frequent and handicapping in schizophrenia spectrum disorders (SSDs). Moreover, they have addressed the problem of the lack of an epistemological and heuristic framework to model disorders of imagination in SSDs. Imagination has been neglected in psychopathology, especially in the contemporary DSM/ICD classifications. This dimension is obliterated in the new classifications of mental disorders in cognitive neurosciences and psychology ( $\mathrm{RDoC} /$ HiTOP) which is an impediment to research and psycho- 
therapy. Rasmussen et al. [1] have developed an instrument for a semistructured phenomenological exploration of anomalous fantasy and imagination [2], opening up the possibility for description and discussion. These disorders are characterized by 3 phenomenological dimensions: (1) perceptualization of imagery: the experience acquires certain quasi-perceptual qualities such as spatialization, spatiotemporal constancy, and explorability; (2) autonomization of imagery with a quasi-involuntary flow and a sense of experiential distance between the conscious image and sense of agency; and (3) erosion of irreality: whereas the imagination is normally lived with an ever-present character of unreality, persons with SSDs could experience vivid imagery without a clear separation with the real world.

They went beyond the clinical description and put forward a conceptual framework for these disorders. They have emphasized the link between minimal self disorders and psychopathology of imagination, thereby fixing the coordinates of the conceptual apparatus supposed to account for those specific clinical phenomena in SSDs.

The aim of the present paper is to discuss this initiative by stressing their paradigm with recent phenomenological research in the philosophical field. Phenomenology refers both to (1) the description of subjective experience, i.e., the what-it-is-like-ness of mental states, and (2) the explicitation of the tacit conditions of possibility of such an experience (transcendental field). In this sense, it is not the individual experience that is in question but the universal structure of consciousness. In contemporary phenomenological research, philosophers have emphasized the imaginary structure of consciousness and self-experience drawing mainly on Husserl's manuscripts on image consciousness [3]. This body of literature can be assembled as the imaginary turn of phenomenological studies. Based on these philosophical theses, we argue that disorders of the imagination are not generated by self disorders but rather that disorders of imagination and fantasy are basic aspects of self disorders, much like diminished selfaffection and hyperreflexivity.

Although this field of research is currently very active in philosophy, to date there are very few translational approaches in psychopathology or cognitive sciences able to tackle the problems of imagination in the phenomenological psychopathology $[4,5]$. In this paper, we examine how contemporary research concerning fantasy and imagination can lead to the elaboration of an epistemological and phenomenological framework for schizophrenia research. We first examine the recent psychopathological literature on anomalous fantasy and imagi-

Imagination and Self Disorders in Schizophrenia nation in SSDs. We then proceed with a review of the literature of the so-called imaginary turn in philosophical phenomenology. Furthermore, we examine the theoretical and practical implications of such a recasting of phenomenological research. Finally, we propose an overview of the possible implications for the understanding of psychotherapeutic processes and recovery strategies.

\section{Psychopathology of Imagination}

Although imagination has globally been overlooked in contemporary psychopathology, Janet [6] and Binet [7] showed very early on the importance of imagination as a function of perceptive experience synthesis (e.g., for the representation of a single object from the images perceived by each visual field) both in neuropathology and normal perception. Bleuler [8] mentioned disorders of imaginary life in his pioneer descriptions of schizophrenia disorders as early as 1911. Schizophrenic autism is a complex symptom combining a detachment from reality with a withdrawal into internal fantasy life. He adds that the autistic (fantastic) world and the real (shared) world can merge in the "most illogical way." This phenomenon was later described as double bookkeeping (doppelte Buchführung) [9]. At the very same moment in France, Dupré and Logre [10] described imaginative delusion derived from physiological imaginative intuition. Later Ey [11] proposed a hierarchical multilayer model of consciousness and psychopathology inspired by Jackson and Janet [12], namely organodynamics [11]. In this conceptualization, of crucial importance in French classical psychopathology, imagination is one of the basic domains of conscious life and relation to reality. Jaspers [13] and Ey [14] had both emphasized the role of imagination in pseudohallucination [13-15]. Since the late 60s, however, very little work has been done on imagination in psychopathology.

Recently, Rasmussen and Parnas [1] have conceptualized the pathology of imagination. They claim that psychiatry lacks the conceptual and descriptive resources to grasp the specificity of the imaginative life of patients. However, they emphasized that imagination is a specific modality of intentionality (act of consciousness); it is related to other intentional modes such as perceiving, thinking, remembering, and feeling. It is indeed already clearly stated by Husserl that fantasy and imagination are not faculties of a subject but modes of appearance, i.e., phenomenological data. That means that for the phenomenological description the question is not how I can fan- 
tasize or imagine something, but rather how something appears as being fantasized or imagined [3], or what it is like to have an image consciousness or a fantasy appearance. Drawing on Husserl, one can describe the phenomenological structure of imagination - as Rasmussen and Parnas also do - by stressing that imagination without any physical support (i.e., a photograph) is an immediate experience of something absent, coupled with the consciousness of unreality and characterized by a floating or protean quality of the appearing experienced data. The phenomenology of imagination can be explicated by drawing the differences between perceptual and imaginative experience. In contrast with empiricist philosophers such as Hume or Locke for whom external stimuli are transformed into contents of the mind by the means of a representation, in Husserl's term, perception gives real objects as immediately and prereflectively present "in the flesh" or "bodily." Contrariwise, when an imaginative idea is present to consciousness, the represented content of the imagination is immediately and prereflectively experienced as something that is not present. When I imagine my next weekend for example, I can have a protean image (idea) of what it will be like, but this vague image is made with and surrounded by an immediate feeling of irreality. It is not here, and it is not perceptible as a scene I might explore as would be the case with a real perceived experience. The same is true of remembering a place or a song. I can imagine the Pantheon, but I cannot count the number of its columns. That is why imaginings are not the same as "pictures in the mind." If I have a meeting with my friend, who is late, and I imagine him coming to the café, I see him in the imaginary appearance I have of him, while being conscious of the fact that he is not here. This imagining of my friend, however, is not a picture in my mind; it is far less detailed than the photo of him that I could look up on my phone via social media; it is undetermined and has a floating quality. I am not able, for example, to examine the details of his haircut or the patterns of his scarf. But paradoxically, I can feel in imaginative anticipation his style of movement and the affective atmosphere he generally carries with him as a vague impression of his presence (nonspecular mimesis). And contrary to a photo or a perception of him, accessible to anyone, only I have access to my imagination as immediate content. There is, in this sense, a privacy of imagination. Only I imagine what I imagine. And there is, for me, no doubt about it. That is why I can effectively lie about it. The I is the ultimate judge of the reality of my imagination; no one else can attest to it. This privacy is lived as an intimacy in the sense that I live my imaginings as if they were in the "space from within" of my experience and not something out there in the shared world available to others. My ordinary experience of reality is a mixture of perceptual and imaginary experiences between which it is difficult to discern. For example, my experience of the lived world is built by sensory data and cultural habits, "clothes of ideas" in the words of Husserl. That is why I can see a whale in a cloud or a god in a river. Of course, if the imagination is experienced as private, it is coded specifically by the person's cultural context. As such, imagination is of crucial importance in daily life.

Rasmussen and Parnas argue that imagination has specific experiential qualities in SSDs with crucial diagnostic relevance and heuristic potential. Patients often report intense, vivid imagery, typically designated as obsessions or pseudo-obsessions as described in DSM-IV. The authors supplement this rudimentary description with an extended description of experiential reports of patients living with SDDs. These data have notably emerged from the numerous empirical studies carried out by Parnas's team on the psychometric phenomenologically inspired instrument EASE [16].

The 3 significant dimensions of anomalies of imagination are:

1 Perceptualization of imagery: the imaginary experience acquires certain quasi-perceptual qualities such as spatialization, spatiotemporal constancy, and explorability.

Example 1. Rasmussen and Parnas quote a 27-year-old woman diagnosed with schizophrenia: "For example I have had the same sequence repeatedly: in great detail, I see someone stepping out on the road in front of my bike, and I run them down. The movie runs constantly, the location of things is very distinct. It is like watching a movie or really seeing an event. I can see the woman I run into, and all the people in the background, all the cars on the other side of the road... I don't feel I evoke the images. They come by themselves and run by themselves." [1]

2 Autonomization of imagery with a quasi-involuntary flow and a sense of experiential distance between the conscious image and sense of agency. Imagination can appear as an involuntary rumination or obsession (sometimes with violent or macabre content).

Example 2. Marguerite is a 19-year-old woman experiencing interference of her thought with the ego-dystonic idea of sexually assaulting the department psychologist. These ideas are presented as obsessions that are not experienced as acoustic-verbal hallucinations. This produces an intense experience of guilt, coupled with the fear of acting without being able to control herself. 
3 Erosion of irreality: whereas the imagination is normally lived with an ever-present character of unreality [17] and privacy, persons with SSDs can experience vivid imagery without a clear separation with the shared world.

Example 3. Paul is a 53-year-old man living with schizophrenia in symptomatic remission. He no longer has verbal acoustic hallucinations or delusions, has a social life, and attends the day hospital. When he is alone in bed, he can spend an hour "thinking about demons," which in the past had been the object of his mystical and paranoid delusions. He may then have "visions" of these supernatural creatures. He knows it is his imagination, and he often enjoys it, yet he can sometimes be frightened by the fact that these imaginary monsters seem to be there, in the flesh. It is often easy to reassure him (contrary to the classic schizophrenic delusions) that they are just his own thoughts, "images in his head."

These 3 notions overlap to the extent that they are based on the same generative disorder.

Rasmussen and Parnas not only describe clinical experiences, they also propose a conceptual model of imagination disorders as the expression of minimal self or ipseity disorders $[1,18]$. The latter is hypothesized to be the underlying generative disorder of schizophrenia, and positive/negative symptoms are derived from this core phenotype. In this view, imagination is understood as a mental domain impacted by the core disorder. This hypothesis is based on the idea that imagination has the same status as all other modes of intentional consciousness (e.g., perceiving or remembering). These authors have also developed a psychometric instrument: Examination of Anomalous Fantasy and Imagination (EAFI) [2]. This tool allows semistructured phenomenological exploration of disorders of imagination with good psychometric qualities [19] and diagnostic discrimination of schizophrenia and schizotypal disorder [20]. These results have not been replicated to date.

Rasmussen and Parnas do not seem to be very strongly influenced by the imaginary turn in phenomenology: they mainly draw on Husserl's manuscripts, with 2 other references from Casey [21] and Sartre [17]. Thus, imagination is treated only as a specific mode of intentionality: imagination and fantasy are understood as specific intentional modes among other modes of consciousness. Consequentially, alterations in imagination appear as a derivative or accessory symptom of a more basic or fundamental disorder of minimal self. In other words, the disturbances of imagination point to more fundamental disorders but are not constitutive of the latter. We argue

Imagination and Self Disorders in Schizophrenia that a more radical interpretation of imagination and fantasy can allow for a more detailed understanding of the lived experience of SSDs.

\section{Imagination and Phantasy as a Core Notion in Contemporary Phenomenology}

How can we think about the relationship between ipseity and imagination? How can we phenomenologically describe the entanglement of perception and imagination in normal and pathological consciousness? Such basic levels of consciousness need a powerful heuristic model able to illuminate the tacit operations of the consciousness that organizes the links between ipseity and imagination. This is all the more challenging in that we are talking about a stratum of experience that is inchoate and very difficult to thematize in words. Such research was carried out by Husserl himself very early in his phenomenological work. Notably in his lectures from 1904-1905 onwards where he addresses the question of the description of the imaginary experiences of consciousness and their phenomenological difference with other experiences, notably perception. Husserl's main problem is the description of what-is-it-like to have image consciousness or fantasies. These manuscripts and original research were not well known before the 1980s. They were not a central field of research for contemporary philosophical historians and phenomenologists before the publication in the 1980s of Husserl's manuscripts on image consciousness, phantasy (that from now on we spell with a $p h$ in accordance with the English translation of Husserl's terminus technicus), and remembering [3]. The various manuscripts dating from different periods of Husserl's own research offer rich material for the phenomenological understanding of imagination and point out several hard problems that the research community has had to face over the last several decades.

These manuscripts are, however, not mere reflections on how imaginary contents can appear, but point to a more fundamental question that prepares the imaginary turn: are not imagination and phantasy always already in play in every experience and, if so, to what extent? When I look at any object or scene, I always dress it up with phantasies: I can see a national hero in a stone statue, I can see Henry VIII in person through the performance of a theatre actor, I can also anticipate the other side of a building that I do not see because I automatically associate it with a similar type of building. This basic function is well described in developmental psychology as the abil- 
ity of the child to play with toys as if the representations were real. It is this question that grounds the imaginary turn in recent phenomenological research. And if imagination and phantasy are at play in every experience, what are the phenomenological criteria to distinguish and identify anomalies in their functioning?

This imaginary turn has been prepared by the previous generations of scholars in phenomenology. The necessity of understanding imagination as a basic dimension of every experience has been recognized by Fink [22] in Representation and image. He insists on the fact that experience is always already imbued with forms of absence (depresentations). For example, my experience of my former self is always given as present in my actual experience although it is not "here" as present. It is the same when I imagine my future. Images represent absent content, and phantasies permit us to build worlds that are present while absent (when I read a book of science fiction for example). Merleau-Ponty [23] has introduced the notion of an oneirism of wakefulness which he elaborates on within the framework of a discussion of psychoanalysis in order to show how symbolic associations in our wakened life can function like those in dreams [pp. 249-279]. However, scholars have only recently undertaken a systematic and in-depth exploration of the functioning of imagination and phantasy in the constitution of lived and embodied experience [24-28]. What is at stake here is to investigate whether imagination and phantasy are derived modes of intentionality and only accidental to the constitution of the lived world, or if we can point out an original stratum of imagination and phantasies that are essential to any experience in general.

Is there something like a pure perception, free from the mist produced by imagination and phantasy, that enables us to access objective reality? Or is reality always already at least partially mediated by imaginary and phantastical modes of appearance? If I miss someone, for example, and I see them in every person on the street or if I see figures in the clouds is it enough to say that I am only reproducing something I have purely perceived?

The spectrum of hypotheses aimed at understanding the entanglement of imagination, phantasy, and perception reach from balanced approaches pointing out the intertwining of different modes of intentionalities with imaginative or phantastical intentionalities [29-31] (perceptive intentionalities are always mixed with imaginative ones) to a more radical understanding of the imaginary constitution of the real [32] (perceptive intentionalities can be derived from imaginative or phantastical ones). What is at stake here, according to a recent formu- lation by Schnell, is a systematic reconsideration of the priority of perceptual intentionality related to other types of intentionalities and, thus, a reconsideration of the role of the objectifying consciousness [27, p. 81;32-36].

Drawing on these authors one can argue that experience is not the superimposition of 2 separate intentional worlds (the real [addressed by perception] and the private [made by imagination]) but that it is about seeing one as if it were the other with an as if structure, therefore not a superimposed but an always hybrid reality. In this sense, imaginary life is not a distortion of reality, rather the experience of reality is always an original distortion of something unapparent. We do not have access to the real in itself, or to a world in its pure reality, but always through imaginary or phantastical structures (which are also culturally coded) that make it understandable, perceptible, habitable, in other words, human. Phantasies and imaginations have a direct impact on how we perceive the world, on what it is like to perceive, making up a part of the content of our perceptions. And are not such imaginary and phantastical appearances always also guiding us through our experiences? For example, when we travel and imagine the road to carry on before the car, or, more generally, when we make plans.

In Richir's project of a refoundation of phenomenology, we can find a rather radical understanding of imagination and phantasy. Richir argues that phantasy has to be understood as the very basic phenomenological layer of consciousness. On the theoretical level, this implies a methodical substitution of the register of phantasy for that of perception [37, p. 227]. Phantasy is no more conceived of as a derived mode of intentionality (being a modification of perception) but becomes the pre-intentional basis of intentionality in general.

This means that the basic and tacit layer of experience is an inchoative appearance of something that is not yet understood as real or unreal, that precedes this distinction: it is an appearance taken for what it is without any spontaneous judgement of its ontological status. A landscape during a hiking trip, for example, can appear as a valley being a half-hour walk away, but also as a beautiful phenomenon impossible to reach, because if we go there it disappears as a landscape and becomes an environment. The Mount St. Victoire is neither real nor imaginary, it is an appearance of phantasy that can be conceived of either as something real, if I actually want to go there, or as something imaginary, like in Cézanne's paintings. We can always see something other than what is, really, there, since the real is always - in the sense of Merleau-Ponty - imminent [36, p. 12, 211-213]. Thanks to 
phantasy we are not riveted to reality as is, for example, an alexithymic personality with operative thinking [38].

A crucial point of Richir's argument is the distinction between phantasy and imagination. Phantasy, imagination, and perception are not only different modes of givenness but also, and more importantly, different strata or layers of experience (this is what Richir calls different levels of the "phenomenological architectonics" [33, 34]), phantasy being at play at the most basic level of phenomenalization that can be transposed into a perception (if it aims at something that is constituted as real) or into an imagination (if it aims at something constituted as fictive or unreal). In short: perception has to deal with a present, imagination with representation, and phantasy with a nonpositional appearance of something that is neither present nor represented. For Richir, phantasy designates a floating and protean appearance without the edification of an image consciousness or a memory on it, like when I remember that I have something to do but I cannot remember what. I have a bizarre feeling of this "something." Then I might finally remember (sometimes passively); I know immediately that it was this specific thing I was searching for. In this sense, phantasy is not a type of reproductive imagination: it is not a copy or a modification of reality but the experiential background on which an imagining or a perception may appear. Phantasy would thus be - in Merleau-Pontian terms - the invisible dimension of the visible side of imagination and perception, it is, so to speak, the negative of imagination and perception that, however, also functions as its matter or hyle [for a more concrete analysis on how phantasy can serve as a hyle for the imaginary intentionality, see 32,39]. And if consciousness is always defined by intentionality, the preintentional register of phantasy has the status of a phenomenological unconscious [27]. Between the stratum of phantasy and that of imagination, there is no possible passage without what Richir calls an architectonic transposition implying a hiatus that manifests itself as a gap in the imaginative figuration. This gap is very important for experience (there is no coincidence in the transposition of phantasy into imagination) because it is where the mineness of this experience can take shape.

\section{Theoretical and Practical Implications}

One of the major implications of such an understanding of phantasy is that it is always embodied. In order to stress this idea, Richir uses the concept of Phantasieleib, of Husserlian origin (which literally means the "flesh of phantasy"). Such a concept implies at the same time the discovery of the embodied dimension of phantasy and imagination, and the discovery of the imaginary and phantastical dimension of corporeality. By this operational concept, Richir emphasized more than Husserl or Sartre the idea that imagination and phantasy are not only spiritual or ideal matters, but they are grounded in the body schema (in Merleau-Ponty's sense in The phenomenology of perception) [40] through kinesthesia.

This idea is crucial not only to understand the embodiment of phantasies and imaginations in general, but also to emphasize the fact that the anomalies of imagination have a direct effect on the body schema and even on the body image of the patients. It also permits an understanding of schizophrenia as a fundamental disturbance of embodied self [41].

Robert is a 40-year-old man living with paranoid schizophrenia in incomplete clinical remission. Despite the care he receives in the day hospital, he continues to be hampered by a delusion of civil war. Everything indicates that he could be the collateral victim of a conflict between black and white people. What handicaps him the most is a feeling of nonexistence. He explains that since childhood he has felt like he was a nonplayer character in a video game (NPC is any character in a game which is not controlled by a player but by an algorithm). He complains that he does not know who he is. The only certainties about himself are that he is fat, slow, and green. "Green like the color... That's why (he's) an environmentalist." In this vignette, we can see that the feeling of disembodiment is coupled with a delusional idea riveted to the external world. The civil war theme works as an imaginary scene which always codifies the experience in a rigid and manichean register. However, in spite of his feeling of nonexistence, he managed to establish 3 characteristics of himself (perhaps delusional but reliable). His body schema is established, fixed, and plasticized in these 3 rudimentary characteristics (green, slow, and fat). Phantasy here is not an opening dimension of self-world relatedness but is rigidified in an imaginary trap that systematically captures every new experience into the delusional register while leaving him without certainty (loss of natural evidence in Blankenburg's terms).

In his phenomenological anthropology, Richir insists on the fact that not only the empirical movements of the body are accompanied by kinesthesia, but also phantasies and even thinking, and these sensations of phantasy movements or movements of thought are anchored in the Phantasieleib and its body schema. I think by the means of kinesthesia of thinking [39, pp. 173-5], as for example, 
the movement of a verb or a metaphor [42]: "I fall asleep," "I follow an idea," "I retain a concept," etc. According to Richir, thinking freely, as an ordinary operation of synthesis, is basically an embodied and a protean form of daydreams. That is, the basic strata of experiencing, thinking, or sensing is made of this field of protokinesthesia not yet structured by objectifying and positional intentionality but still bushy and moving.

According to the concept of the Phantasieleib, the body schema itself is embedded in phantasy, which does not mean that it is a representation or an image of the body. It is rather a phantasy that mediates the relation between the self and the world. More precisely, we can define body schema as an embodied schematism of phenomenalization which is not a fixated and figurative schema as would be the body image. So, if we can make a phenomenological distinction between phantasy and imagination, the same kind of relationship can be described between body schema and body image. In relation to identity, the same relationship is described by Ricoeur between identity ipse (minimal self) and identity idem (sameness). We can argue that the body schema is the element of the protean embodied ipseity, whereas the body image is the element of its identification and thus of the institution of its identity. Therefore, ipseity is always phantastical, whereas identity is always imaginary. In the situation of Robert, his embodied and protean self is rigidified and stiffened into the identity of a rudimentary body image. That is why he cannot know more about himself than what the image represents. His relation to himself is mediated by this image (paradoxically lived without mediation), which does not allow for easy adaptation to the ever-changing conditions of the environment. It also does not allow for the ability to re-invent and re-narrate oneself to support an experiential recovery process.

According to this hypothesis, the field of consciousness consists of kinesthetic possibilities and phantasy. Furthermore, if the body does not only feel but can feel itself feeling, then this "reflexivity" is mediated by protean phantasy. Self-manifestation is not fixed and complete as an image or a perception, but always moving and unfixable (similarly to the "visage" of the Other in Emmanuel Levinas). We cannot have a definitive idea of who we are. That is why we do not have a definitive image of ourselves as idem identity, but a protean feeling of being. That is also why we can never exactly situate ourselves at a geometrical point in the lived space (are we behind our eyes or in our touching hands?), although we are always somewhere, and, more precisely, we always inhabit our "abso- lute here" [43,pp. 251-270, 44] as the autocoincident center of feeling, perceiving, and thinking, etc.

What Rasmussen and Parnas precisely described as anomalous phantasy and imagination in SSDs are not mere accessory symptoms of basic self disorders. Richir's perspective enables us to strongly link 2 major currents in phenomenological psychopathology of SSDs: the ipseity disorders [18] and the embodiment disorders [41, 45, 46] via the phenomenology of embodied phantasy. Such a link should not lead to a confusion of both, but it should shed light on their intimate connection and synergy, making it possible to elaborate a phenomenological framework in which the different descriptive approaches find their place. According to Richir, SSDs are characterized by a transformation of living corporeality [47] and affectivity [48]. Such a metamorphosis implies a rigidification of the originally protean Phantasieleib, which loses its original constitutive fluidity and, thus, is lived as a quasi-object. This transposition of the body schema functioning in the Phantasieleib in a plastified, quasi-material body image results in a rigidification of a still inchoative field of affectivity [48]. This rigidification makes experience appear as if it was happening without the participation of the self, because no reflexivity can appear without the Phantasieleib. For Robert, this dimension appears as he speaks of himself as of a nonplayer character in a video game: he does not control his "character," but is controlled by the algorithms of a game functioning without the intimacy of the experience lived from within. Thus, the embodied experience appears as if there was no longer any intimacy other than a radical passivity lived as suffering.

Consequently, the rigidification of the Phantasieleib implies a disorder of the "absolute here," of the embodied self that is no more related to an original form of spatiality in phantasy, but is transposed in a quasi "absolute there" from whence the experience seems to be prescribed for the self rather than lived by it. This phenomenon can also be clearly seen in what Conrad calls Wahnstimmung [49] and was recently described by Fusar-Poli et al. [50] as "Truman" symptoms. The sense of unreality of the world is coupled with the false appearance of it as if it were made up. Richir describes the phenomenological structure behind such experiences with the notion of Phantomleib, i.e., the transposition of the Phantasieleib into its rigidified form, resulting in an "atmospherisation of the absolute here" [34, p. 342, 51] which can lead to reverse intentionality in paranoid delusion and hallucination $[52,53]$.

The anomalies of imagination and phantasy described by Rasmussen and Parnas are in our view manifestations 
of the transposition of the Phantasieleib in a Phantomleib. The externalization or plastification of the inner space is due to a transposition of phantasy kinesthesia lived from within into kinesthesia that is prescribed (by a delusional other) from the outside. Correlatively, protean phantasies are transposed into images that unfold by themselves in a quasi-mechanical way (as in a conspiracy where everything would be played out in advance, as a diabolical machination). Spatiality depends on embodiment, and embodiment is originarily embodiment in a Phantasieleib. In this view, the Phantasieleib is the anonymous stratum of ipseity and consciousness, the field on which the minimal self appears to itself. But it is not a direct auto-affection, as in Henry, but a foggy space of encounter full of phantasies. So, we would like to hypothesize that the generating disorder of schizophrenia should not only be "located" at the level of the self, however minimal, but also at the stratum below, in the basement, so to speak, which is "made" of this yet inchoative and asubjective mixture of phantasy and corporeality. In other words, schizophrenia could be understood as a disorder of the Phantasieleib. Such a framework is the result of a genuinely phenomenological construction that goes beyond the description of the phenomena in order to reveal the architectonics of the phenomenological discourse in psychopathology, by distinguishing the different layers or strata of the lived experience from the deepest constitutive and asubjective layer to the more explicit, symbolically coded form of experience. This not only has heuristic interest but also potential therapeutic implications.

\section{Discussion}

One might wonder why it is necessary to raise the issue of phantasy in schizophrenia and always dig deeper and deeper into the strata of experience. At the end of the day, "what" is more originary: Minimal self? Embodiment? Phantasy? And what does knowing bring us? In our view, the phenomenological understanding of imaginary life has possible implications, not only for descriptive psychopathology, but also for the understanding of psychotherapeutic processes and recovery. Scholars have recently emphasized in this journal the implication of phenomenology in conceptualizing psychotherapeutic processes $[54,55]$, and we would like to go in that direction.

If we have described the anomalies of Phantasieleib in schizophrenia, we should also ask the question: what is the consequence of the encounter with another Phantasieleib? The implication of phantasy and embodiment in

Imagination and Self Disorders in Schizophrenia the intersubjective relationship sheds a new light on this specific intersubjective encounter that is therapy. Indeed, phantasy and imagination are not only private matters, but make up an intersubjective space in which they can be exchanged, shared, and this at the very level of corporeality. We can hypothesize that the therapist (in classical face-to-face psychotherapy, in dance movement therapy, or in milieu psychotherapy) is sharing their Phantasieleib with the patients. That is why one can feel, in a certain way, the embodied condition of the other in a very basic way (for example of bizarreness [56]). It is the Phantasieleib that makes understanding possible in Jaspers' sense. It also enables one to make the experience of the patient intuitively present (anschauliche Vergegenwärtigung): it is by accompanying the expressions of the other with kinesthesia in phantasy (nachbilden) that the therapist is able to comprehend actively (nachvollziehen) the world of the other as a first person perspective. This "as if" function is mediated by the tacit process of metaphorization enabled by the Phantasieleib. In this way, the task of psychotherapy is not only to explore and understand the patient's lived world but also to reopen their horizon of embodied possibilities [57]. In this sense, those concepts are not about "phenomenological psychotherapy" but a heuristic device which can serve as a framework for conceptualizing and modeling more rigorously therapeutic processes in general.

Finally, we would like to stress the implication of phantasy in the process of experiential recovery for a person living with schizophrenia. As a matter of fact, people describe a renewal and a reappropriation of values and lifestyles which correspond to personal norms and narratives [58]. In this experience, numerous scholars and advocates emphasized the importance of narrative exchanges $[59,60]$ as a link between different processes of restoring the power of acting (empowerment) and selfredefinition. Insofar as the stories making up our narrative identity are indeed always mixtures of memories and fiction, phantasy plays a major role in the possibility of forming and performing them. Further research might explore the correlation between anomalies of imagination, phantasy, and aptitude for recovery. Moreover, caregivers might take phantasy life as a therapeutic target of intervention to support experiential recovery in users.

\section{Acknowledgment}

We want to thank Tucker Frederick Kapp for his very careful proofreading of this text and philosophical suggestions. 


\section{Statement of Ethics}

No patient was involved in this review article. Clinical vignettes of patients were anonymized.

\section{Conflict of Interest Statement}

The authors have no conflicts of interest to declare.

\section{Funding Sources}

This paper was not funded.

\section{Author Contributions}

Tudi Gozé and Istvan Fazakas contributed equally to this paper (joint first authors).

\section{References}

1 Rasmussen AR, Parnas J. Anomalies of imagination and disordered self in schizophrenia spectrum disorders. Psychopathology. 2015; 48(5):317-23.

2 Rasmussen AR, Stephensen H, Parnas J. EAFI: Examination of anomalous fantasy and imagination. Psychopathology. 2018;51(3): 216-26.

3 Husserl E. Phantasie, Bildbewußtsein, Erinnerung. Zur Phänomenologie der anschaulichen Vergegenwärtigung. Texte aus dem Nachlass (1898 - 1925) (Hua XXIII). Den Haag: Martinus Nijhoff; 1980.

4 Richir M: De la figuration en psychopathologie. Rev Port Filos. 2011;67(3):569-578.

5 Murakami Y. Affection of contact and transcendental telepathy in schizophrenia and autism. Phenomenol Cogn Sci. 2013;12(1):179-94.

6 Janet P: L'automatisme psychologique. Essai de psychologie expérimentale sur les formes inférieures de l'activité humaine. Paris, Société Pierre Janet et Laboratoire de Psychologie Pathologique de la Sorbonne, 1973 (1889).

7 Binet A. Sur les rapports entre l'hémianopsie et la mémoire visuelle. Rev Philos France Let. 1888;2:481-8.

8 Bleuler E. Dementia praecox or the group of schizophrenias. New York: International University Press; 1950. [Originally published in 1911.].

9 Cermolacce M, Despax K, Richieri R, Naudin J. Multiple realities and hybrid objects: a creative approach of schizophrenic delusion. Front Psychol. 2018 Feb;9(107):107.

10 Dupré E, Logre J. Les délires d'imagination, mythomanie délirante. Encephale. 1911;4: $430-50$.

11 Ey H. Etudes psychiatriques. Paris: Desclée de Brouwer; 1948.12 Janet P. La force et la faiblesse psychologique. Paris: Maloine; 1932.

13 Jaspers K. General psychopathology. Chicago: University of Chicago Press; 1963.

14 Ey H. Traité des hallucinations. Paris: Masson; 1973.

15 Berrios GE, Dening TR. Pseudohallucinations: a conceptual history. Psychol Med. 1996 Jul;26(4):753-63.

16 Parnas J, Møller P, Kircher T, Thalbitzer J, Jansson L, Handest P, et al. EASE: Examination of anomalous self-experience. Psychopathology. 2005 Sep-Oct;38(5):236-58.
17 Sartre JP. The imaginary: a phenomenological psychology of the imagination. London: Routledge; 2010. https://doi.org/10.4324/ 9780203857069.

18 Sass LA, Parnas J. Schizophrenia, consciousness, and the self. Schizophr Bull. 2003;29(3): $427-44$.

19 Rasmussen AR, Stephensen H, Nordgaard J, Parnas J. A phenomenological approach to psychopathology of imagination: development of a descriptive instrument - examination of anomalous fantasy and imagination. Psychopathology. 2018;51(3):210-5.

20 Rasmussen AR, Sæbye D, Parnas J. Anomalies of imagination in the schizophrenia-spectrum: empirical findings. Schizophr Res. 2019 Apr;206:458-9.

21 Casey ES. Imagination, phantasy, hallucination and memory. In: Philips J, Morley J, editors. Imagination and its pathologies. Cambridge: MIT Press; 2003. pp. 65-92.

22 Fink E. Vergegenwärtigung und Bild. Beiträge zur Phänomenologie der Unwirklichkeit. In: Studien zur Phänomenologie 19301939. Phaenomenologica. Dordrecht: Springer; 1966. Vol 21. p. 1-78.

23 Merleau-Ponty M. L'institution, la passivité. Notes de cours au Collège de France (19541955). Paris: Belin; 2015.

24 Sallis J. Force of imagination: the sense of the elemental. Bloomington: Indiana University Press; 2000. https://doi.org/10.2307/j. ctt1zxz13n.

25 Sallis J. Logic of imagination: the expanse of the elemental. Bloomington: Indiana University Press; 2012.

26 Morley J. Introduction: phenomenology of imagination. Phenomenol Cogn Sci. 2005; 4(2):117-20.

27 Schnell A. La déhiscence du sens. Paris: Hermann; 2015.

28 Schnell A. Wirklichkeitsbilder. Tübingen: Mohr Siebeck; 2015

29 Lohmar D. Phänomenologie der schwachen Phantasie: Untersuchungen der Psychologie, Cognitive Science, Neurologie und Phänomenologie zur Funktion der Phantasie in der Wahrnehmung. Dordrecht: Springer; 2008.

30 Lohmar D. On the function of weak phantasmata in perception: phenomenological, psychological and neurological clues for the tran- scendental function of imagination in perception. Phenomenol Cogn Sci. 2005;4(2): $155-67$.

31 Jansen JA. On the development of Husserl's transcendental phenomenology of imagination and its use for interdisciplinary research. Phenomenol Cogn Sci. 2005;4(2): 121-32.

32 Dufourcq A. La dimension imaginaire du réel dans la philosophie de Husserl. Dordrecht: Springer; 2011. https://doi.org/10.1007/97890-481-9797-2.

33 Richir M. Phénoménologie en esquisses. Grenoble: Millon; 2000.

34 Richir M. Phantasia, imagination, affectivité Grenoble: Millon; 2004.

35 Dufourcq A, editor. Est-ce réel? Phénoménologies de l'imaginaire. Boston: Brill; 2016.

36 Dufourcq A. Merleau-Ponty: une ontologie de l'imaginaire. Dordrecht: Springer; 2011.

37 Richir M. Variations sur le sublime et le soi. Grenoble: Millon; 2010.

38 Marty P. La psychosomatique de l'adulte. Paris: Presses Universitaires de France; 2004.

39 Richir M. De la négativité en phénoménologie. Grenoble: Millon; 2014.

40 de Saint Aubert E. Être et chair. Du corps au désir l'habilitation ontologique de la chair. Paris: Vrin; 2013.

41 Fuchs T. Corporealized and disembodied minds: a phenomenological view of the body in melancholia and schizophrenia. Philos Psychiatry Psychol. 2005;12:95-107.

42 Binswanger L. Traum und Existenz. In: Ausgewählte Werke, Bd. 3. Vorträge und Aufsätze. Heidelberg: Roland Asanger Verlag; 1994. p. 95-119.

43 Husserl E. The world of the living present and the constitution of the surrounding world external to the organism. In: McCormick P, Elliston FA, editors. Husserl: shorter works. Notre Dame, IN: University of Notre Dame Press; 1981. p. 251-70.

44 Fazakas I, Gozé T. The promise of the world - towards a transcendental history of trust. Husserl Stud. 2020;36(2):169-89.

45 Grohmann T. Corps et monde dans l'autisme et la schizophrénie: approches ontologiques en psychopathologie. Dordrecht: Springer; 2019. https://doi.org/10.1007/978-3-03014395-4. 
46 Tschacher W, Giersch A, Friston K. Embodiment and schizophrenia: a review of implications and applications. Schizophr Bull. 2017 Jul;43(4):745-53.

47 Richir M. Stimmung, Verstimmung et Leiblichkeit dans la Schizophrénie. Conferências de Filosofia II. Porto: Campo das Letras; 2000.

48 Gozé T, Grohmann T, Naudin J, Cermolacce $M$. New insight into affectivity in schizophrenia: from the phenomenology of Marc Richir. Psychopathology. 2017;50:401-7.

49 Mishara AL. Klaus Conrad (1905-1961): delusional mood, psychosis, and beginning schizophrenia. Schizophr Bull. 2010 Jan; 36(1):9-13.

50 Fusar-Poli P, Howes O, Valmaggia L, McGuire $\mathrm{P}$. 'Truman' signs and vulnerability to psychosis. Br J Psychiatry. 2008 Aug; 193(2):168.

51 Fazakas I. Le labyrinthe d'air. La structure des fantasmes dans l'anthropologie phénoménologique de Marc Richir. In: Popa D, Bodea
C, editors. Describing the unconscious. Phenomenological perspectives on the subject of psychoanalysis. Bucharest: Zeta Books; 2020. p. 177-200.

52 Fuchs T, Schlimme JE. Embodiment and psychopathology: a phenomenological perspective. Curr Opin Psychiatry. 2009 Nov;22(6): 570-5.

53 Azorin JM, Naudin J. The hallucinatory epoché. J Phenomenological Psychol. 1997; 28(2):171-95.

54 Fuchs T, Messas GP, Stanghellini G. More than just description: phenomenology and psychotherapy. Psychopathology. 2019;52(2): 63-6.

55 Fuchs T. The interactive phenomenal field and the life space: a sketch of an ecological concept of psychotherapy. Psychopathology. 2019;52(2):67-74.

56 Gozé T, Moskalewicz M, Schwartz MA, Naudin J, Micoulaud-Franchi JA, Cermolacce M.
Reassessing "praecox feeling" in diagnostic decision making in schizophrenia: a critical review. Schizophr Bull. 2019 Sep;45(5):96670.

57 Fuchs T. Psychotherapy of the lived space: a phenomenological and ecological concept. Am J Psychother. 2007;61(4):423-39.

58 Davidson L. Living outside mental illness: qualitative studies of recovery in schizophrenia. New York: NYU Press; 2003.

59 Lysaker PH, Buck KD, Roe D. Psychotherapy and recovery in schizophrenia: a proposal of key elements for an integrative psychotherapy attuned to narrative in schizophrenia. Psychol Serv. 2007;4(1):28-37.

60 Stanghellini G, Lysaker PH. The psychotherapy of schizophrenia through the lens of phenomenology: intersubjectivity and the search for the recovery of first- and second-person awareness. Am J Psychother. 2007;61(2):16379. 